\title{
Embriões bovinos PIV vitrificados em diferentes soluções crioprotetoras com ou sem o uso de nitrogênio super-resfriado*
}

\author{
Bovine IVP embryos vitrified in different cryoprotectant \\ solutions, using or not super cooled nitrogen \\ Dennys Eduardo Werlich ${ }^{1}$, Marcos Henrique Barreta'2 ${ }^{2}$ Leonardo Tondello Martins ${ }^{2}$,
Arnaldo Diniz Vieira ${ }^{3}$, Aury Nunes de Moraes ${ }^{3}$ \& Alceu Mezzalira
}

\begin{abstract}
RESUMO
O total aproveitamento de embriões PIV ainda depende de uma metodologia eficiente de criopreservação. Este estudo avaliou a taxa de eclosão de embriões bovinos PIV, vitrificados em OPS usando três diferentes soluções crioprotetoras (Experimento 1) e o emprego de nitrogênio normal $\left(-196^{\circ} \mathrm{C}\right)$ ou super-resfriado $\left(-210^{\circ} \mathrm{C}\right)$ (Experimento 2). No primeiro experimento (12 repetições) 576 blastocistos expandidos (Bx) PIV foram aleatoriamente alocados em 4 grupos: G1 (20\% EG + 20\% DMSO), G2 (25\% EG + 25\% GLI), G3 (20\% EG + 20\% PRO) e G4 (controle não vitrificado). Após 72 horas de cultivo in vitro, a taxa de eclosão do grupo controle $(84,0 \%)$ foi superior às observadas nos grupos vitrificados $(\mathrm{P}<0,05)$. Não houve diferença na eclosão do $\mathrm{G} 1(53,5 \%)$ e G3 (52,8\%), que foram superiores ( $\mathrm{P}<0,05)$ ao $\mathrm{G} 2$ (38,9\%). No segundo experimento (5 repetições), $244 \mathrm{Bx}$ foram aleatoriamente expostos às soluções $\mathrm{EG}+\mathrm{DMSO}(\mathrm{G} 1$ e G2) ou EG+PRO (G3 e G4), para avaliar o emprego de nitrogênio líquido super-resfriado pela submissão ao vácuo $\left(-210^{\circ} \mathrm{C}\right)$. Não houve diferença $(\mathrm{P}>0,05)$ nas taxas de eclosão de embriões vitrificados com nitrogênio super-resfriado ( $\mathrm{G} 2=50,2 \%$ e G4=54,0\%) ou nitrogênio normal ( $\mathrm{G} 1=50,1 \%$ e G3=56,0\%), independente da solução crioprotetora empregada. Conclui-se que as soluções compostas por EG+DMSO e EG+PRO possibilitam taxas de eclosão similares e são mais eficientes que a solução EG+GLI. O emprego do nitrogênio super-resfriado não aumenta a viabilidade pós-vitrificação de blastocistos bovinos PIV.
\end{abstract}

Descritores: vácuo, nitrogênio super-resfriado, OPS, vitrificação, embriões PIV, bovinos.

\section{ABSTRACT}

An adequate methodology of cryopreservation may proportionate the maximum use of IVP embryos. The aim of this study was to determine the viability of bovine IVP expanded blastocysts (Bx) vitrified in OPS with tree different cryoprotectant solutions (Experiment 1), under normal $\left(196^{\circ} \mathrm{C}\right)$ or super-cooled $\left(-210^{\circ} \mathrm{C}\right)$ liquid nitrogen (Experiment 2$)$. Hatching rate was considered as viability parameter. In the first experiment (12 replications), IVP Bx ( $\mathrm{n}=576)$ were randomly allocated into 4 groups: Group I (20\% EG + 20\% DMSO), Group II (25\% EG + 25\% GLY), Group III (20\% EG + 20\% PRO) and Group IV (control not vitrified). After 72 hours of culture, control group hatching rate $(84.0 \%)$ was higher $(\mathrm{P}<0.05)$ than that observed with the vitrified experimental groups. There were no differences between hatching rates observed in Groups I (53.5\%), and III (52.8\%), and both were higher than Group II (38.9\%). In the second experiment ( 5 replications) $244 \mathrm{Bx}$ were randomly exposed to EG+DMSO (GI and GII) or EG+PRO (GIII and GIV) solutions in order to evaluate the use of super-cooled liquid nitrogen by vacuum submission. There were no differences among the hatching rates of embryos vitrified with super-cooled (GII $=50.2 \%$ and GIV $=54.0 \%$ ) or normal nitrogen $(\mathrm{GI}=50.1 \%$ and $\mathrm{GIII}=56.0 \%)$, independently of the solutions. In conclusion, the EG+DMSO and EG+PRO solutions were similar on promoting IVP Bx survival after vitrification, and they were more efficient than the EG+GLY solution. The use of super cooled liquid nitrogen did not improve embryo survival after vitrification.

Key words: vacuum, cooled nitrogen, OPS, vitrification, IVP embryos, bovine. 


\section{INTRODUÇÃO}

O Brasil tem se destacado na produção in vitro (PIV) de embriões bovinos, existindo hoje um excedente de embriões em relação à capacidade de transferência direta para receptoras. Semelhante ao que ocorre com embriões produzidos in vivo, onde cerca de $50 \%$ são congelados [23], uma adequada metodologia de criopreservação para os excedentes, poderia maximizar a utilização de embriões PIV. Entretanto, as estruturas produzidas atualmente são deficitárias e mais sensíveis à criopreservação do que os produzidos in vivo $[6,9,10$, $16,19]$. Isto torna o método convencional de congelamento inadequado para a criopreservação de embriões PIV [8,16,19], principalmente em função do excessivo tempo de exposição à faixa térmica correspondente à solidificação dos lipídios [31]. A metodologia mais promissora para criopreservar esses embriões é a vitrificação [2,7,16,22,24,25], que em função de sua maior velocidade de resfriamento e aquecimento proporciona uma passagem rápida pela faixa crítica de temperatura. Diversas metodologias de vitrificação foram desenvolvidas, empregando diferentes soluções crioprotetoras, diferentes tipos de suporte para acondicionamento dos embriões e diferentes velocidades de resfriamento, o que dificulta a comparação dos dados dos distintos experimentos.

O objetivo deste estudo foi determinar as taxas de eclosão de embriões bovinos PIV vitrificados no estágio de blastocisto expandido (Bx), empregando a metodologia OPS com o uso das soluções Etileno Glicol (EG) + Dimetil sulfóxido (DMSO), EG + Glicerol (GLI) ou EG + 1,2 Propanediol (PRO), bem como avaliar o emprego de nitrogênio líquido normal ou super-resfriado.

\section{MATERIAIS E MÉTODOS}

Exceto onde indicado, todos os reagentes foram obtidos da Sigma Chemical Co. ${ }^{1}$ Nas manipulações de oócitos e embriões foram utilizadas placas de quatro poços obtidas da Nunc. $\mathrm{S} / \mathrm{A}^{2}$.

A produção in vitro dos embriões foi baseada em metodologia descrita previamente por Mezzalira e colaboradores [15]. Resumidamente, ovários bovinos coletados em abatedouros e transportados a $35^{\circ} \mathrm{C}$ em solução salina tamponada com fosfato (PBS), tiveram seus folículos com diâmetro entre 2 e $8 \mathrm{~mm}$ puncionados. Os complexos cumulus-oócitos recuperados foram mantidos em líquido folicular centrifugado, sendo selecionados de acordo com suas características morfológicas. Grupos de 30 oócitos foram incubados por 24 horas em atmosfera de $5 \%$ de $\mathrm{CO}_{2}$ e máxima umidade em estufa a $39^{\circ} \mathrm{C}$. A fecundação foi obtida mediante incubação por 18-20 horas com 1 x $10^{6}$ espermatozóides, selecionados pelo método de migração ascendente "swim-up". Após, procedeu-se a remoção das células do cumulus mediante agitação mecânica e a transferência dos prováveis zigotos para o meio de cultivo SOFaaci [4] + 5\% de soro de égua em estro (SEE). A determinação da taxa de clivagem foi realizada após 24 horas de cultivo em atmosfera de 5\% de $\mathrm{CO}_{2}$. A partir de então o cultivo das estruturas clivadas foi efetuado em atmosfera úmida de $5 \%$ de $\mathrm{CO}_{2}, 5 \%$ de $\mathrm{O}_{2}$ e $90 \%$ de $\mathrm{N}_{2}$ usando bolsas impermeáveis a gases [26], mantidas em estufa a $39^{\circ} \mathrm{C}$, por mais 162 horas. Ao final do período de cultivo, os Bx classificados com o grau 1 ou 2 [3] foram homogeneamente divididos entre os grupos experimentais.

A vitrificação dos embriões foi baseada em tecnologia descrita previamente [28], utilizando-se as diferentes soluções crioprotetoras e/ou temperaturas de resfriamento, de acordo com o tratamento, sendo envasados três embriões em cada OPS. O meio TCMHepes (TCM-199 + 25 mM Hepes + 10\% de SEE) foi utilizado como base na preparação das soluções contendo DMSO, sendo que este foi adicionado apenas no momento do uso. As demais soluções foram preparadas previamente, usando como base o meio de Dulbeccos (D-PBS) adicionado de $10 \%$ de SEE. Estas soluções foram fracionadas e armazenadas em freezer a $-17^{\circ} \mathrm{C}$, em tubos com capacidade de $1,5 \mathrm{~mL}$, sendo descongeladas no momento do uso.

No primeiro experimento, 576 embriões foram divididos em 4 grupos: Grupo I (EG+DMSO), com exposição por 1 minuto a uma solução de $10 \% \mathrm{EG}+$ $10 \%$ DMSO, seguida da exposição por 20 segundos à solução de vitrificação (20\% EG + 20\% DMSO). No Grupo II (EG+GLI), os embriões foram expostos por 5 minutos a $10 \%$ GLI, seguido de 1 minuto em uma solução de $10 \%$ GLI + 20\% EG, e finalmente expostos por 30 segundos à solução de vitrificação (25\% GLI + $25 \%$ EG). No Grupo III (EG+ PRO), com exposição por 1 minuto a uma solução de $10 \% \mathrm{EG}+10 \% \mathrm{PRO}$, seguido da exposição por 20 segundos à solução de vitrificação (20\% EG + 20\% PRO). No Grupo IV (controle), embriões não vitrificados foram utilizados como controle da viabilidade.

No segundo experimento, 244 embriões foram vitrificados com as soluções selecionadas do experi- 
mento 1, (EG+DMSO e EG+PRO) usando nitrogênio líquido normal $\left(-196^{\circ} \mathrm{C}\right)$ ou super-resfriado $\left(-210^{\circ} \mathrm{C}\right)$. Como controle, foram utilizados embriões não vitrificados.

O super-resfriamento do nitrogênio líquido $\left(\mathrm{N}_{2} \mathrm{~L}\right)$ foi obtido com o equipamento Nitrocooler, confeccionado a partir de uma bomba de sucção adaptada a uma câmara de metal com tampa hermética, contendo em seu interior um recipiente de isopor com aproximadamente $300 \mathrm{~mL}$ de $\mathrm{N}_{2} \mathrm{~L}$. Por ação do vácuo ( 5 min) o nitrogênio foi resfriado até o início de sua solidificação $\left(-210^{\circ} \mathrm{C}\right)$. Logo após a abertura da câmara hermética, o nitrogênio retornava ao estado líquido, porém mantendo-se estável, sem emissão de vapor, por um período de até 10 minutos. Durante este período, três OPS contendo os embriões foram sequencialmente imersas no $\mathrm{N}_{2} \mathrm{~L}$ super-resfriado. Antes do novo acionamento do equipamento, as OPS foram transferidas para outro recipiente contendo $\mathrm{N}_{2} \mathrm{~L}$ normal (em ebulição), onde permaneciam em média por 30 minutos até o início do processo de reaquecimento.

Para o reaquecimento, as OPS contendo os embriões foram expostas ao ar por quatro segundos e em seguida mergulhadas na solução de reaquecimento (TCM-Hepes + sacarose) com temperatura aproximada de $35^{\circ} \mathrm{C}$. A remoção da solução EG+DMSO, foi feita com dois períodos de exposição ( 5 minutos cada) em gradientes de 0,3 e 0,15 $\mathrm{M}$ de sacarose, respectivamente. Já a remoção das soluções EG+GLI e EG+PRO foram feitas com dois períodos de exposição (5 minutos cada) em gradientes de 0,6 e $0,3 \mathrm{M}$ de sacarose, antes de passarem ao meio de manutenção (TCMHepes). Após, os embriões de cada grupo foram submetidos a 72 horas de cultivo em meio SOFaaci $+5 \%$ SEE a $39^{\circ} \mathrm{C}$ em estufa com atmosfera de $5 \%$ de $\mathrm{CO}_{2}$ e umidade relativa saturada. A avaliação da viabilidade foi procedida após 72 horas de cultivo, tendo como parâmetro a taxa de eclosão.

\section{Análise estatística}

Os dados dos diferentes grupos foram submetidos à análise de variância com a utilização do pacote estatístico Bioestat e as diferenças das médias submetidas ao teste de Tukey, com nível de significância de $5 \%$.

\section{RESULTADOS}

No experimento 1 , os embriões do Grupo controle (não vitrificados) apresentaram taxa de eclosão
$(84,0 \%)$ superior $(\mathrm{P}<0,05)$ aos grupos vitrificados. Nos grupos vitrificados, as maiores taxas de eclosão foram observadas no Grupo I $($ EG+DMSO $=53,5 \%)$ e Grupo III $(\mathrm{EG}+\mathrm{PRO}=52,8 \%)$. O Grupo II $(\mathrm{EG}+\mathrm{GLI})$ apresentou taxa de eclosão inferior $(38,9 \%)$ aos demais grupos $(\mathrm{P}<0,05)$, como é demonstrado na Tabela 1 .

\begin{tabular}{|c|c|c|c|}
\hline \multirow{2}{*}{ Tratamentos } & \multirow{2}{*}{$\begin{array}{l}\text { Embriões } \\
\text { recuperados } \\
\text { (n) }\end{array}$} & \multicolumn{2}{|c|}{ Taxa de eclosão } \\
\hline & & $\mathbf{N}$ & (\%) \\
\hline Grupo I - EG+DMSO & 144 & 77 & $53,5^{\mathrm{a}}$ \\
\hline Grupo II - EG+GLI & 144 & 56 & $38,9^{b}$ \\
\hline Grupo III - EG+PRO & 144 & 76 & $52,8^{a}$ \\
\hline Controle - Não vitrificado & 144 & 121 & $84,0^{\circ}$ \\
\hline
\end{tabular}

No experimento 2, também observou-se maior viabilidade $(\mathrm{P}<0,05)$ do grupo controle não vitrificado $(83,8 \%)$, não sendo observadas diferenças entre as taxas de eclosão dos grupos EG+DMSO $(50,1 \%)$ ou $\mathrm{EG}+\mathrm{PRO}(56,0 \%)$ vitrificados em $\mathrm{N}_{2} \mathrm{~L}$ normal $\left(-196^{\circ} \mathrm{C}\right)$, com resultados muito próximos daqueles obtidos no primeiro experimento, como demonstra a Tabela 2. A utilização de $\mathrm{N}_{2} \mathrm{~L}$ super-resfriado não melhorou as taxas de eclosão dos embriões vitrificados com EG+DMSO $(50,2 \%)$ ou com EG+PRO $(54,0 \%)$.

\section{DISCUSSÃO}

Apesar de haver certo grau de regeneração embrionária após 24 horas de cultivo [28], a redução na taxa de eclosão dos embriões dos grupos vitrificados em relação aos controles caracteriza danos que comprometem o posterior desenvolvimento dos embriões. Neste estudo, as taxas de eclosão dos grupos controle $(84,0$ e $83,8 \%)$ foram superiores $(\mathrm{P}<0,05)$ às observadas nos grupos vitrificados do experimento $1(38,9$ a $53,5 \%)$ e experimento $2(50,1$ a $56,0 \%)$, respectivamente. Entretanto, estudos [18] sugerem que essa diferença pode ser eliminada caso o sistema de cultivo pré e pós-vitrificação forneça adequadas condições de desenvolvimento para os embriões [18]. As soluções de vitrificação, compostas por EG+DMSO e EG+PRO, nas condições deste experimento, proporcionaram as 


\begin{tabular}{lccc}
$\begin{array}{l}\text { Tabela 2. Taxa média de eclosão de blastocistos bovinos PIV vitrificados com dife- } \\
\text { rentes soluções crioprotetoras, com o emprego de }\end{array}$ & $\mathrm{N}_{2} \mathrm{~L}$ normal ou super-resfriado. \\
\hline Tratamentos & $\begin{array}{c}\mathbf{N}_{2} \text { L super- } \\
\text { resfriado }\end{array}$ & $\begin{array}{c}\text { Embriões } \\
\text { recuperados } \\
\text { (n) }\end{array}$ & $\begin{array}{c}\text { Taxa de Eclosão } \\
\text { (\%) }\end{array}$ \\
\hline GI - EG+DMSO & Não & 49 & $50,1^{\mathrm{a}}$ \\
GII - EG+DMSO & Sim & 46 & $50,2^{\mathrm{a}}$ \\
GIII - EG+PRO & Não & 50 & $56,0^{\mathrm{a}}$ \\
GIV - EG+PRO & Sim & 50 & $54,0^{\mathrm{a}}$ \\
Controle não vitrificado & - & 49 & $83,8^{\mathrm{b}}$ \\
\hline a,b $\mathrm{L}$ etras diferentes indicam efeito significativo $(\mathrm{P}<0,05)$. &
\end{tabular}

melhores taxas de eclosão $(53,5$ e $52,8 \%)$, demonstrando que ambas podem ser empregadas com sucesso na vitrificação de blastocistos bovinos PIV. A associação EG+GLI proporcionou baixa taxa de eclosão $(38,9 \%)$ após a vitrificação, diferente dos dados de literatura, onde taxas de eclosão de 59,6\% são relatadas, após vitrificação de embriões bovinos PIV [12]. Em experimento subsequiente e utilizando $25 \% \mathrm{EG}+$ $25 \%$ GLI, são relatadas taxas de $45 \%$ de eclosão, com significativo acréscimo $(66,6 \%)$ após adição de $0,1 \mathrm{M}$ de sacarose, na vitrificação de embriões PIV [13]. Neste estudo, não foi utilizada sacarose na solução de vitrificação, sendo oportunos novos ensaios que avaliem esta possibilidade. As observações que o DMSO, EG e PRO permeiam facilmente as células, ao contrário do glicerol que tem menor permeação e é menos efetivo [5], estão em acordo com os dados aqui obtidos.

Em relação aos protocolos avaliados, dados da literatura exibem grande variabilidade e freqüentes contradições de resultados, o que sugere a influência de fatores como os meios de cultivo, a formulação das soluções, ou mesmo a procedência dos embriões. Embriões PIV cultivados em meio CR1 são mais precoces, porém mais sensíveis ao congelamento do que embriões cultivados em TCM 199 [6]. A utilização dos meios KSOM e SOF, em uso seqüencial, determinou maior viabilidade em relação ao uso isolado [16]. Estes embriões foram mais sensíveis ao congelamento convencional $(30 \%)$, do que à vitrificação $(60 \%)$, demonstrando que mesmo o uso seqüencial dos meios não foi capaz de produzir embriões com a qualidade dos produzidos in vivo, que suportam o congelamento convencional [16].

Neste estudo, as taxas de eclosão obtidas no grupo vitrificado com EG+DMSO (50,1 a 53,5\%) fo- ram semelhantes às obtidas previamente, 47,1\% [14], 49,6 e 54\% [15], em nosso laboratório. Taxas de eclosão de 70,0\% são relatadas com idêntica metodologia [18], com os autores relatando eclosão de $90,2 \%$, quando os embriões foram produzidos em meio condicionado por células da granulosa, no sistema "well of the well", sugerindo uma melhora na criotolerância [18]. Em relação ao presente estudo, as maiores taxas de eclosão podem, ao menos em parte, dever-se a origem dos embriões utilizados pelos autores (Bos taurus indicus), que tem menor teor lipídico em relação aos Bos taurus taurus [30], o que interfere na criotolerância. A idêntica viabilidade observada com o emprego das soluções EG+ DMSO e EG+PRO, nas condições deste experimento, sugere que ambas podem ser empregadas com sucesso na criopreservação de embriões bovinos Bos taurus taurus PIV, com a metodologia OPS. Entretanto, a possibilidade do preparo prévio da associação EG+PRO, confere maior agilidade ao processo e deve ser considerado, no momento de escolha do protocolo.

O super-resfriamento do nitrogênio líquido tem se mostrado viável na criopreservação de oócitos bovinos. Resultados expressivos de desenvolvimento embrionário (38\%), após a vitrificação de oócitos bovinos maturados, foram relatados com o emprego de vácuo [1]. $\mathrm{Na}$ vitrificação de oócitos bovinos imaturos ou maturados, também houve aumento da viabilidade com o emprego de nitrogênio super-resfriado [20,21]. No experimento 2 foram utilizados os protocolos que produziram as melhores taxas de eclosão (EG+DMSO e EG+PRO), associados ao emprego de vácuo. O equipamento proporcionou a solidificação do nitrogênio líquido, com o conseqüente super-resfriamento e o bloqueio da ebulição, o que está em acordo com relatos descritos anteriormente [1,11]. Porém, diferente dos re- 
sultados observados previamente com oócitos [1,20], a utilização de nitrogênio super-resfriado não aumentou a viabilidade dos embriões PIV vitrificados, com EG+DMSO (50,2\% x 50,1\%) ou com EG+PRO (54,0\% x 56,0\%). Isto pode ter sido determinado pelo distinto comportamento osmótico dos embriões, que são constituídos por mais de uma centena de células que respondem individualmente às mudanças osmóticas, determinando maior relação superfície/volume e conseqüentemente maior capacidade de permeação do que os oócitos. Assim, mesmo com menor velocidade de resfriamento, é possível que tenha havido suficiente permeação de crioprotetores nas células, para uma adequada vitrificação, diferente do que ocorre em células maiores, como os oócitos. Também com embriões murídeos no estágio de pró-núcleo, não foi observado efeito significativo do nitrogênio super-resfriado na criopreservação [17]. Embora os autores tenham trabalhado com embriões de espécie e estágio (pró-núcleo) diferentes, estas estruturas apresentam um reduzido vo- lume, o que deve ter determinado o mesmo comportamento observado neste experimento. Estes fatos evidenciam a necessidade de novos estudos avaliando o emprego de nitrogênio super-resfriado, com menores concentrações de crioprotetores, na vitrificação de embriões bovinos PIV.

\section{CONCLUSÕES}

As soluções EG+PRO e EG+DMSO são similares na manutenção da sobrevivência de blastocistos expandidos bovinos após a vitrificação, sendo mais eficientes que a solução EG+GLI, nas condições deste estudo.

O uso de nitrogênio líquido super-resfriado não melhora a viabilidade pós vitrificação de blastocistos bovinos PIV.

\section{NOTAS INFORMATIVAS}

${ }^{1}$ Sigma Chemical Co., St. Louis, MO, USA.

${ }^{2}$ Nunc. S/A, Roskilde, Denmark.

\section{REFERÊNCIAS}

1 Arav A., Zeron Y. \& Ocheretny A. 2000. A new device and method for vitrification increases the cooling rate and allows successful Cryopreservation of bovine Oocytes [Abstract]. Theriogenology. 53: 248.

2 Bautista J.A.N. \& Kanagawa H. 1998. Current status of vitrification of embryos and oocytes in domestic animals: Ethylene glycol as an emerging cryoprotectant of choice. Journal of Veterinary Research. 45: 1183-1191.

3 Hasler J.F., Henderson W.B., Hutgen P.J., Jin Z.Q., MacCauley A.D., Mawer A.S., Neely B., Shuey L.S., Stokes J.E. \& Trimmer S.A. 1995. Production, freezing and transfer of bovine IVF embryos and subsequent calving results. Theriogenology. 43: $141-152$

4 Holm P., Booth P.J., Schmidt M.H., Greve T. \& Callesen H. 1999. High bovine blastocyst development in a static in vitro production system using SOFaa medium supplemented with sodium citrate and myo-inositol with or without serumproteins. Theriogenology. 52: 683-700.

5 Hubálek Z. 2003. Protectants used in the Cryopreservation of microorgamisms. Cryobiology. 46: 205-229.

6 Imai K., Matoba S., Dochi O. \& Shimoira T. 2002. Different factors affect competence and cryotolerance in in vitro produced bovine embryos. Journal of Veterinary Medical Science. 64: 887-891.

7 Ishimori H., Takahashi Y. \& Kanagawa H. 1992. Viability of vitrified mouse embryos using various cryoprotectant mixtures. Theriogenology. 37: 481-487.

8 Kaidi S., Berard S., Lambert P., Massip A., Dessy F. \& Donnay I. 2001. Effect of conventional controlled-rate freezing and Vitrification on morphology and metabolism of bovine blastocysts produced in vitro. Biology of Reproduction. 65: 1127-1134.

9 Lee E.S., Okamoto Y., Yamashina H., Fukui Y. 1997. Pregnancy rates after transfer of fresh or frozen bovine blastocysts developed from serum-free or protein-free media. Theriogenology. 47: 350.

10 Lonergan P., Rizos D., Kanka J., Nemcova L., Mbale A.M., Kingston M., Wade M., Duffy P. \& Boland M.P. 2003. Temporal sensitivity of bovine embryos to culture environment alter fertilization and the implications for blastocyst quality. Reproduction. 126: 333-346.

11 Martino A., Songsasen N. \& Leibo S.P. 1996. Development into blastocysts of bovine oocytes cryopreserved by ultrarapid cooling. Biology of Reproduction. 54: 1059-1069.

12 Martinez A.G., Matos D.G., Furnus C.C. \& Brogliatti G.M. 1998. In vitro evaluation and pregnancy rates after Vitrification of in vitro produced bovine embryos. Theriogenology. 50: 757-767. 
13 Martinez A.G., Valcárcel A. \& de la Heras M.A. 2002. Vitrification of in vitro produced bovine embryos: In vitro and in vivo evaluations. Animal Reproduction Science. 73: 11-21.

14 Mezzalira A., Thaler NetoA., Barbieri D.P., Machado M.F., Vieira A.D., Rubin M.I.B. \& Lehmkuhl R.C. 2001. Vitrificação de embriões bovinos produzidos PIV tratados com citocalasina B. Revista Brasileira de Reprodução Animal. 25: $422-423$.

15 Mezzalira A., Mezzalira J.C., Moraes A.N., Thaler Neto A., Vieira A.D., Barreta M.H. \& Damiani J.C. 2004 Vitrification of bovine embryos: Age of embryos and exposure time to cryoprotectant influences viability. Archives of Veterinary Science. 9: 107-111.

16 Nedambale T.L., Dinnyés A., Groen W., Dobrinsky J.R., Tian X.C. \& Yang Y. 2004. Comparison of in vitro fertilized bovine embryos cultured in KSOM or SOF and cryopreserved by slow freezing or Vitrification. Theriogenology. 62: 437-449.

17 Nowshari M.A. \& Brem G. 2001. Effect of freezing rate and exposure time to cryoprotectant on the development of mouse pronuclear stage embryos. Human Reproduction. 16: 2368-2373.

18 Pereira D.C., Dode M.A.N. \& Rumpf R. 2005. Evaluation of different culture systems on the in vitro production of bovine embryos. Theriogenology. 63: 1131-1141.

19 Pollard J.W. \& Leibo S.P. 1994. Chilling sensitivity of mammalian embryos. Theriogenology. 41: 101-106.

20 Santos R.M., Barreta M.H., Mezzalira J.C., Paulini F., Cruz F.B., Vieira A.D. \& MezzaliraA. 2004. Vitrificação de ovócitos bovinos em nitrogênio líquido com atmosfera normal ou vácuo. Acta Scientiae Veterinariae. 32 (Suplemento): 251. errata.

21 Santos R.M. 2005. Criopreservação de ovócitos bovinos por vitrificação. 29f. Lages, SC. Dissertação (Mestrado em Ciências Veterinárias) Centro de Ciências Agroveterinárias, Universidade do Estado de Santa Catarina.

22 Sommerfeld V. \& Niemann H. 1999. Cryopreservation of bovine in vitro produced embryos using Ethylene glycol in controlled freezing or vitrification. Cryobiology. 38: 95-105.

23 Thibier M. 2003. More than half a milion bovine embryos transferred in 2002. Embryo Transfer Newsletter. 21: 12-19.

24 Vajta G., Booth P.J., Holm P., Greve T. \& Callesen H. 1997. Successful vitrification of early-stage bovine in vitro produced embryos with the open pulled straw (OPS) method. Cryo-letters. 18: 191-195.

25 Vajta G., Holm P., Greve T. \& Callesen H. 1997. Survival and development of bovine blastocysts produced in vitro after hatching, vitrification and in-straw direct rehydration. Journal of Reproduction and Fertility. 111: 65-70.

26 Vajta G. Holm P. Greve T. \& Callesen H. 1997. The Submarine Incubation System, a new tool in vitro embryo culture. A technique report. Theriogenology. 48: 1379-1385.

27 Vajta G., Hyttel P. \& Callesen H. 1997. Morphological changes of in-vitro produced bovine blastocysts after vitrification, in-straw direct rehydration, and culture. Molecular Reproduction and Development. 48: 9-17.

28 Vajta G., Holm P., Kuwayama M., Booth P.J., Jacobsen H., Greve T. \& Callesen H. 1998. Open Pulled Satraw (OPS) vitrification: a new way to reduce cryoinjuries of bovine ova and embryos. Molecular Reproduction and Development. $51:$ 53-58.

29 Vajta G., Rindom N., Peura T.T., Holm P., Greve T. \& Callesen H. 1999. The effect of media, serum and temperature on in vitro survival of bovine blastocysts after open pulled straw (OPS) vitrification. Theriogenology. 52: 939-948.

30 Visintin J.A., Martins J.F.P., Bevilacqua E.M., Mello M.R.B., Nicácio A.C. \& Assumpção M.E.O.A. 2002. Cryopreservation of Bos taurus vs Bos indicus embryos: Are they really different? Theriogenology. 57: 345-359.

31 Zeron Y., Pearl M., Borochov A. \& Arav A. 1999. Kinetic and temporal factors influence chilling injury to germinal vesicle and mature bovine oocytes. Cryobiology. 38: 35-42. 